\title{
GOAL CHARACTERIZATION AFTER BALL RECOVERY IN PLAYERS OF BOTH GENDERS OF FIRST LEAGUE SOCCER TEAMS IN PORTUGAL
}

original paper

(1) University School of Physical Education in Wroclaw

DOI: https://doi.org/10.5114/hm.2018.81288

\section{MARIO ESPADA ${ }^{1,2}$, CAMILA FERNANDES ${ }^{1}$, CARLOS MARTINS $^{1}$, HUGO LEITAO ${ }^{1}$, TERESA FIGUEIREDO ${ }^{1,3}$, FERNANDO SANTOS ${ }^{1,3}$}

${ }^{1}$ School of Education, Polytechnic Institute of Setúbal, Setúbal, Portugal

${ }^{2}$ Interdisciplinary Center for the Study of Human Performance, Lisbon, Portugal

${ }^{3}$ Life Quality Research Center, Santarém, Portugal

\section{ABSTRACT}

Purpose. This study intends to analyse game situations from the recovery of the ball to goal achievement in the Portuguese first league professional male and female soccer players.

Methods. The goals (total 58) of women's (29) and men's (29) first league Portuguese professional soccer teams were observed. The coding of the actions was performed with the Lince computer program, on the basis of a goal observation system in soccer. Descriptive analysis and comparisons were carried out with the chi-square test by Monte Carlo simulation.

Results. The women's team recovered the ball preferably by interception, in the middle central offensive zone, with the last pass stepwise more frequent in the central zone and offensive right, through the fast attack and finalization with the right foot. The men's team recorded more occurrences of ball recovery through disarming, in the middle central defensive and offensive zone, and the goals were obtained as a result of the last pass in the right offensive zone and without pass for finalization because of fast attacks, and predominantly with the right foot. Statistically significant differences were observed between the male and female teams in the technical-tactical action of interception for ball recovery.

Conclusions. The soccer game dynamics and goal achievement by the male and female first league professional Portuguese teams present differences that should be assumed in training and competition preparation.

Key words: goal, soccer, gender, first league

\section{Introduction}

Soccer is a team sport, involving many players. It requires an efficient collective organization and, simultaneously, specific development of each player with the consideration of individual and group perspective. Traditional research in this sport divides players into four groups: goalkeepers, defenders, midfielders, and forwards [1, 2].

Tactical, physical, and technical skills [3, 4] successfully discriminate soccer players by competitive level and position. It has previously been demonstrated that the behaviour of players can be influenced by the scoreline $[5,6]$.
Soccer is characterized by a successive alternation of states of order and disorder, stability and instability, uniformity and variety [7]. To enhance a team's goal scoring ability, coaches and players aim to define and implement attacking strategies that are more likely to result in a goal outcome [8]. These attacking strategies are often specific to the position on the field where possession of the ball is gained and are intended to position the ball in the attacking quarter of the field to promote shots at goal [9].

Although there is much information on the technical aspects of the sport [10], the scarcity of data on the tactical aspects is evident, especially in women's soccer. Its inclusion in the program of the Olympic

Correspondence address: Mário Espada, School of Education, Polytechnic Institute of Setúbal, Campus do IPS, Estefanilha 2914 - 504 Setúbal, Portugal, e-mail: mario.espada@ese.ips.pt

Received: September 30, 2018

Accepted for publication: December 27, 2018

Citation: Espada M, Fernandes C, Martins C, Leitao H, Figueiredo T, Santos F. Goal characterization after ball recovery in players of both genders of first league soccer teams in Portugal. Hum Mov. 2018;19(5)special/issue:73-81; doi: https://doi. org/10.5114/hm.2018.81288. 
M. Espada, C. Fernandes, C. Martins, H. Leitao, T. Figueiredo, F. Santos, Goal characterization in soccer

Games in Atlanta in 1996 should be regarded as a turning point in the development of women's soccer, although it is worth mentioning that, as exemplified in Iran, it still faces great difficulties [11].

Actually, it is unanimous that the moments of changing ball possession involve behaviours which are important to the match. Ball recovery, the foremost aim of the defensive phase [12], is a brief or even instantaneous action, and it is simultaneously the first stage of the attack. Successful ball recovery depends on good defensive performance, although it may also result from attacking errors [13]. After ball recovery, teams compete to get advantage in time and space, developing individual and collective behaviours to improve their own organization levels and to decrease the opponent team's balance [14]. It therefore seems essential to be aware of the constraints that affect ball recovery patterns, that is, how and where the ball is regained and the influence this has on subsequent patterns of attacking play.

Ball recovery patterns have been studied to a minor extent, with a common focus on the zones where the ball is recovered and how they relate to the efficacy of any subsequent attack [15]. Thus, the influence of the zone in which the ball is recovered and its relationship to attack efficacy has been determined [16-18].

Some studies have concluded that ball recovery in offensive zones during open play rarely results in goals [19], the latter occurring primarily owing to ball recovery in the middle defensive sector. In relation to the attacking configuration which follows ball recovery, research has shown that a fast shift from defence to attack, with an almost instantaneous exploitation of the ball, benefits the efficacy of the attack [20].

Previously, it was stated that attacks starting in offensive zones of the pitch were more likely to result in a goal or a goal-scoring opportunity [21, 22]. Consequently, attacking success is associated with fast recovery of the ball in offensive zones [23].

The attacking strategies that have been shown to be effective in men's soccer may not be appropriate when applied to women's game. Accordingly, the performance analysis of effective attacking strategies in women's game is warranted.

However, in reviewing the literature, it is noted that scarce attention has been paid to research that considers gender difference in the tactical aspects of soccer. This study intends to analyse game situations from the recovery of the ball to goal achievement in Portuguese first league professional male and female soccer players.

\section{Material and methods}

\section{Sample}

The sample consisted of goals in the Portuguese professional senior male $(n=29)$ and female $(n=29)$ first league, the total of 58 goals. The goals relate to the 2017-2018 season in single professional male and female soccer teams. The games were chosen by convenience to analyse the same number of goals by gender. The observation and analysis of the goals was performed from the recovery of the ball to the finalization, goal achievement.

\section{Instruments}

The instrument used to encode the game actions that culminated in goal was a goal observation system in soccer (Table 1), previously validated [24] and applied in research with the same objective [25].

\section{Procedures}

The goals were collected through the Wyscout platform and the Portuguese Football Federation, as well as through the official channel of the first league soccer team. The observation and coding of the goals was performed with the Lince ${ }^{\circledast}$ computer program [26].

\section{Reliability}

In order to guarantee the quality of the data, we previously carried out the study of intra- and inter-observer reliability [27]. In this way, we followed the procedures defined for the training of observers and the study of reliability [28]. The reliability values were obtained with the $\kappa$-Cohen agreement [29], and the values were collected for all the criteria above the 0.96 .

\section{Data analysis}

In data processing, the IBM SPSS Statistics ${ }^{\circledR}$ computer program was used. Descriptive analysis was performed, and the occurrence of each behaviour depending on gender was determined with the chi-square test. Since one of the conditions for the strict application of the chi-square test was not verified $(n>20)$, we used the chi-square test by Monte Carlo simulation [30] with the level of significance of $p<0.01$. 
Table 1. Goal watching system in soccer

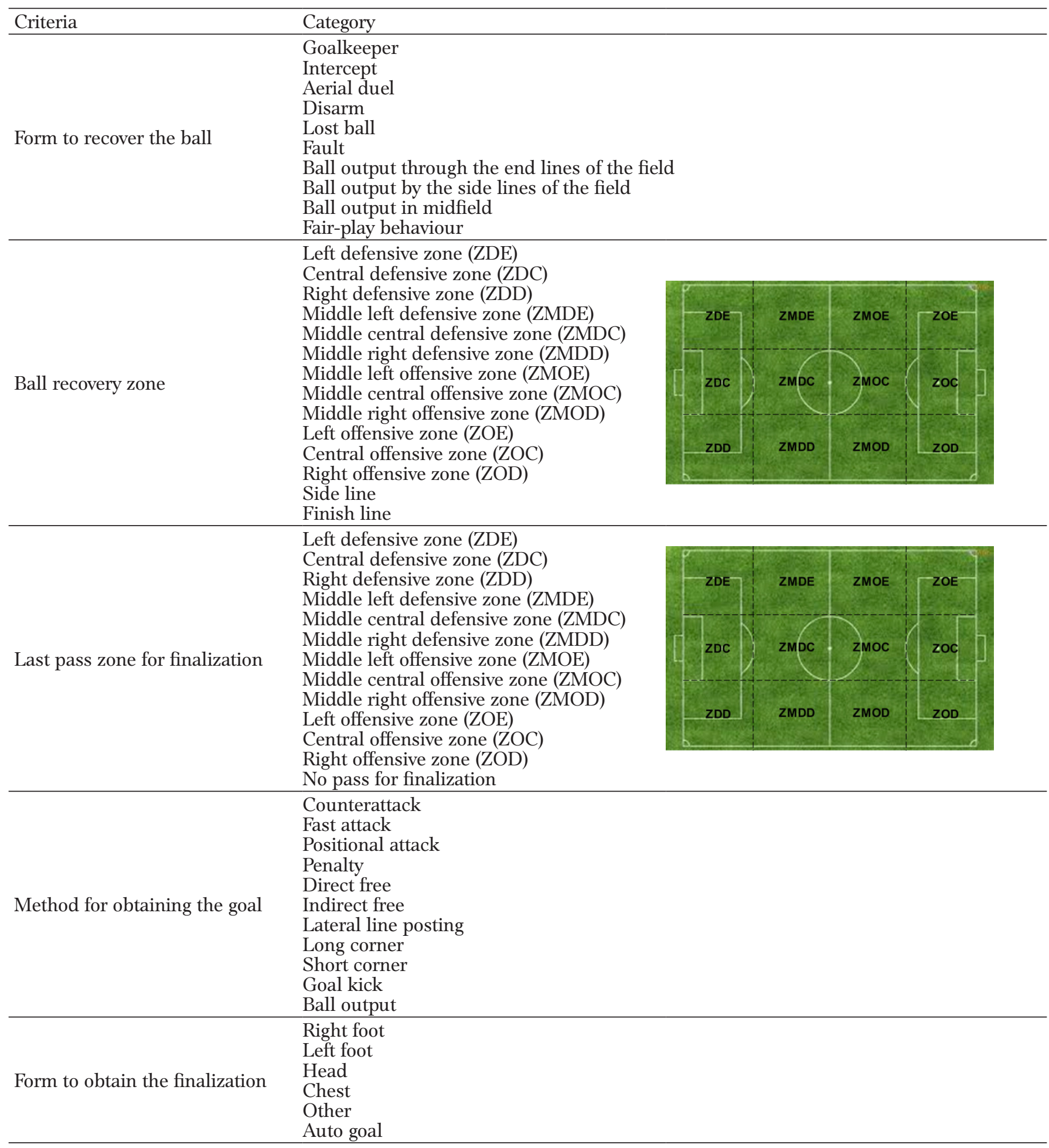

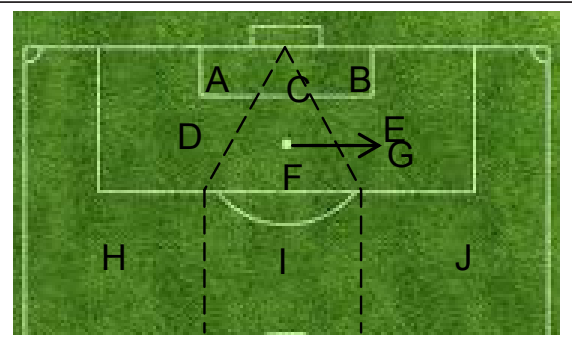


M. Espada, C. Fernandes, C. Martins, H. Leitao, T. Figueiredo, F. Santos, Goal characterization in soccer

\section{Ethical approval}

The conducted research is not related to either human or animal use.

\section{Results}

The presented results are related to goals scored by a male and a female team of professional soccer first league. The results depict the way that the two teams reached the finalization of created situations since the recovery of the ball.

Table 2 presents the analysis of the form of ball recovery before goal achievement among both male and female soccer players. The difference between genders is clear and refers to the criteria of 'intercept,' 'disarm,' 'fault,' and 'ball output through the end lines of the field'. However, only in 'intercept' was the difference between genders statistically significant.

Also, the analysis of the ball recovery zone before goal achievement (Table 3 ) reveals a tendency in male soccer to utilize the central sector of the ground before success in finalization, contrarily to the female team, where the recovery of the ball took place in the most advanced zones of the playing field, namely the offensive zone.

Table 4 present data related to the last pass zone for finalization. We found differences in the total value in men's and women's soccer. It is clearly observable that in women's soccer, the last pass is predominantly in the offensive zone, and in men's soccer, there is a better balance between the middle and offensive zone.

In none of the genders, goals scored with a previous

Table 2. Analysis of the form of ball recovery

\begin{tabular}{|c|c|c|c|c|c|}
\hline \multirow{2}{*}{ Criterion } & \multicolumn{2}{|c|}{ Female team } & \multicolumn{2}{|c|}{ Male team } & \multirow{2}{*}{$p$} \\
\hline & Sum & $\%$ & Sum & $\%$ & \\
\hline Goalkeeper & 1 & 3.45 & 0 & 0 & 0.182 \\
\hline Intercept & 11 & 37.93 & 0 & 0 & $0.001 *$ \\
\hline Aerial duel & 1 & 3.45 & 0 & 0 & 0.182 \\
\hline Disarm & 7 & 24.14 & 12 & 41.38 & 0.443 \\
\hline Lost ball & 5 & 17.24 & 6 & 20.69 & 0.418 \\
\hline Fault & 2 & 6.90 & 6 & 20.69 & 0.302 \\
\hline Ball output through the end lines of the field & 0 & 0 & 4 & 13.79 & 0.074 \\
\hline Ball output by the side lines of the field & 1 & 3.45 & 1 & 3.45 & 0.696 \\
\hline Ball output in midfield & 1 & 3.45 & 0 & 0 & 0.182 \\
\hline Fair-play behaviour & 0 & 0 & 0 & 0 & $\mathrm{a}$ \\
\hline
\end{tabular}

* significant differences for $p<0.01$ with the chi-square test by Monte Carlo simulation a - statistics not calculated owing to variable being constant

Table 3. Analysis of the ball recovery zone

\begin{tabular}{|c|c|c|c|c|c|}
\hline \multirow{2}{*}{ Criterion } & \multicolumn{2}{|c|}{ Female team } & \multicolumn{2}{|c|}{ Male team } & \multirow{2}{*}{$p$} \\
\hline & Sum & $\%$ & Sum & $\%$ & \\
\hline Left defensive zone & 0 & 0 & 0 & 0 & $\mathrm{a}$ \\
\hline Central defensive zone & 1 & 3.45 & 0 & 0 & 0.182 \\
\hline Right defensive zone & 0 & 0 & 0 & 0 & $\mathrm{a}$ \\
\hline Middle left defensive zone & 1 & 3.45 & 0 & 0 & 0.182 \\
\hline Middle central defensive zone & 1 & 3.45 & 6 & 20.69 & 0.091 \\
\hline Middle right defensive zone & 0 & 0 & 2 & 6.90 & 0.242 \\
\hline Middle left offensive zone & 1 & 3.45 & 5 & 17.24 & 0.182 \\
\hline Middle central offensive zone & 8 & 27.59 & 6 & 20.69 & 0.084 \\
\hline Middle right offensive zone & 2 & 6.90 & 4 & 13.79 & 0.790 \\
\hline Left offensive zone & 5 & 17.24 & 1 & 3.45 & 0.055 \\
\hline Central offensive zone & 6 & 20.69 & 1 & 3.45 & 0.234 \\
\hline Right offensive zone & 3 & 10.34 & 1 & 3.45 & 0.074 \\
\hline Side line & 0 & 0 & 1 & 3.45 & 0.424 \\
\hline Finish line & 1 & 3.45 & 2 & 6.90 & 0.869 \\
\hline
\end{tabular}

${ }^{a}$ statistics not calculated owing to variable being constant 
Table 4. Analysis of last pass zone for finalization

\begin{tabular}{|c|c|c|c|c|c|}
\hline \multirow{2}{*}{ Criterion } & \multicolumn{2}{|c|}{ Female team } & \multicolumn{2}{|c|}{ Male team } & \multirow{2}{*}{$p$} \\
\hline & Sum & $\%$ & Sum & $\%$ & \\
\hline Left defensive zone & 0 & 0 & 0 & 0 & a \\
\hline Central defensive zone & 0 & 0 & 0 & 0 & $\mathrm{a}$ \\
\hline Right defensive zone & 0 & 0 & 0 & 0 & a \\
\hline Middle left defensive zone & 1 & 3.45 & 0 & 0 & 0.182 \\
\hline Middle central defensive zone & 1 & 3.45 & 0 & 0 & 0.182 \\
\hline Middle right defensive zone & 0 & 0 & 0 & 0 & $\mathrm{a}$ \\
\hline Middle left offensive zone & 1 & 3.45 & 4 & 13.33 & 0.330 \\
\hline Middle central offensive zone & 3 & 10.34 & 2 & 6.67 & 0.210 \\
\hline Middle right offensive zone & 0 & 0 & 2 & 6.67 & 0.242 \\
\hline Left offensive zone & 4 & 13.79 & 4 & 13.33 & 0.411 \\
\hline Central offensive zone & 7 & 24.14 & 3 & 10 & 0.236 \\
\hline Right offensive zone & 7 & 24.14 & 6 & 20 & 0.484 \\
\hline No pass for finalization & 5 & 17.24 & 9 & 30 & 0.834 \\
\hline
\end{tabular}

${ }^{\mathrm{a}}$ statistics not calculated owing to variable being constant

Table 5. Analysis of the methods for goal achievement

\begin{tabular}{|c|c|c|c|c|c|}
\hline \multirow{2}{*}{ Criterion } & \multicolumn{2}{|c|}{ Female team } & \multicolumn{2}{|c|}{ Male team } & \multirow{2}{*}{$p$} \\
\hline & Sum & $\%$ & Sum & $\%$ & \\
\hline Counterattack & 1 & 3.45 & 3 & 10.34 & 0.551 \\
\hline Fast attack & 15 & 51.72 & 14 & 48.28 & 0.464 \\
\hline Positional attack & 10 & 34.48 & 7 & 24.14 & 0.080 \\
\hline Penalty & 2 & 6.90 & 2 & 6.90 & 0.551 \\
\hline Direct free & 0 & 0 & 2 & 6.90 & 0.242 \\
\hline Indirect free & 0 & 0 & 0 & 0 & $\mathrm{a}$ \\
\hline Lateral line posting & 0 & 0 & 0 & 0 & a \\
\hline Long corner & 1 & 3.45 & 1 & 3.45 & 0.696 \\
\hline Short corner & 0 & 0 & 0 & 0 & $\mathrm{a}$ \\
\hline Goal kick & 0 & 0 & 0 & 0 & $\mathrm{a}$ \\
\hline Ball output & 0 & 0 & 0 & 0 & $\mathrm{a}$ \\
\hline
\end{tabular}

a - statistics not calculated owing to variable being constant

pass from the defensive zone were noted. Another evidence is that in males, there are more goals without a pass before the finish than those obtained after passing in the middle zone; in females, the number of goals obtained without a pass before is also considerable.

The most common methods for goal achievement were 'fast attack' and 'positional attack,' as observed in Table 5.

Goals were predominantly obtained with the right foot, and only 2 with the head in females versus 5 in male soccer players (Table 6), an aspect to be considered in the specific and tactical preparation of competition.

Table 7 presents the finishing zones. We observed a large difference in zone I (central zone outside the area), with 5 goals in males and 2 for female players. Zones C, F, and I, the central zones of the attack, were
Table 6 . Analysis of the way to obtain the goal

\begin{tabular}{lccccc}
\hline \multirow{2}{*}{ Criterion } & \multicolumn{2}{c}{ Female team } & \multicolumn{2}{c}{ Male team } & \multirow{2}{*}{$p$} \\
\cline { 2 - 5 } & Sum & $\%$ & Sum & $\%$ & \\
\hline Right foot & 20 & 68.97 & 19 & 65.52 & 0.464 \\
Left foot & 6 & 20.69 & 5 & 17.24 & 0.560 \\
Head & 2 & 6.90 & 5 & 17.24 & 0.328 \\
Chest & 0 & 0 & 0 & 0 & a \\
Other & 0 & 0 & 0 & 0 & a \\
Auto goal & 1 & 3.45 & 0 & 0 & 0.182 \\
\hline
\end{tabular}

a - statistics not calculated owing to variable being constant 
M. Espada, C. Fernandes, C. Martins, H. Leitao, T. Figueiredo, F. Santos, Goal characterization in soccer

Table 7. Analysis of the finalization zone

\begin{tabular}{lcrcrc}
\hline \multirow{2}{*}{ Criterion } & \multicolumn{2}{c}{ Female team } & \multicolumn{2}{c}{ Male team } & \\
\cline { 2 - 4 } & Sum & \multicolumn{1}{c}{$\%$} & Sum & $\%$ & \\
\hline Zone A & 2 & 6.90 & 3 & 10.34 & 0.411 \\
Zone C & 6 & 20.69 & 2 & 6.90 & 0.238 \\
Zone B & 1 & 3.45 & 1 & 3.45 & 0.696 \\
Zone D & 5 & 17.24 & 5 & 17.24 & 0.491 \\
Zone F & 7 & 24.14 & 9 & 31.03 & 0.701 \\
Zone E & 1 & 3.45 & 0 & 0 & 0.182 \\
Zone G & 2 & 6.90 & 2 & 6.90 & 0.551 \\
Zone H & 0 & 0 & 0 & 0 & $\mathrm{a}$ \\
Zone I & 2 & 6.90 & 5 & 17.24 & 0.726 \\
Zone J & 3 & 10.34 & 2 & 6.90 & 0.359 \\
\hline
\end{tabular}

a - statistics not calculated owing to variable being constant

areas in which more goals were obtained in total and in both genders. Despite this, no statistically significant differences were observed between genders.

In zone $\mathrm{C}$, the closest to the goal, a greater number of goals were obtained by females as compared with male soccer players.

\section{Discussion}

This study intends to analyse game situations from the recovery of the ball to goal achievement in Portuguese first league professional male and female soccer players. Soccer performance research is broadly developed and implemented [31], contributing to a rapid and continuous enhancement of players' performance in the recent few years [16]. Soccer is a multifaceted sport, in which success depends on several physical, technical, and tactical factors [32].

The overall tactics of soccer entail a permanent interrelationship between the patterns of attacking and defensive play [33]. Previously, it was observed that transitions could be trained to improve the patterns of play and probably reduce the game uncertainty and increase this attitude-changing efficacy [34, 35].

In this decade, it has been indicated that the imbalances of the opposition team resulting from ball losses in the process of defence-attack transition, because of the pressing performed in the offensive midfield, are among the most common causes of goal [17]. More recently it has been observed that teams tend to recover the ball directly in the central middle defensive zone, and less frequently in the defensive and middle offensive zones, which corroborates the findings of a study in Euro 2008 [14].
A similar trend was reported by the analysis of Portuguese and European teams; it was found that ball possession was most often regained in the central strip of the midfield sector [21]. In relation to findings such as these, a study suggested that elite teams conventionally regarded ball recovery in middle defensive zones as fundamental because it enabled the ideal defensive organization to be preserved [7].

In a study carried out in order to analyse goals obtained by elite teams belonging to the European leagues, it was verified that goals resulted from ball recoveries in zones of the offensive midfield [24]. In the present study, male soccer players tended to recover the ball in the central sector of the ground before goal achievement, contrary to the female players, who recovered the ball in the most advanced zones of the playing field.

These facts clearly reveal different strategies in the pressure on the ball bearer and in the team's collective movement according to gender, aspects that apparently must be assumed in the dynamics of the daily training process. We also observed differences between men and women regarding the recovery of the ball, namely statistically significant differences in 'intercept,' but also different values in 'disarm,' 'fault,' and 'ball output through the end lines of the field'.

A rapid attack results from a rapid defence-attack transition; however, the creation of finishing situations occurs with the opposing team organized in its defensive method [36]. Several previous studies have shown that despite the teams' attempts to elaborate their attack (positional attack), it is through the counterattack that more opportunities and goal achievements take place [24, 37-39]. The results in the present study in relation to the goal-scoring method point to very close values between genders, with a higher incidence of fast attack and positional attack.

The decreasing number of free kicks occurring with reduced distance to the opponents' goal can be explained by the fact that these zones cannot be reached as often [40]. Another reason could be that fouls are risked less when defending players are closer to their own goal. This, in turn, can result from the weighing of the danger of a goal from a possible free kick against the consequences of losing a challenge for the ball [41].

As shown in the existing literature, goals are obtained, from the highest frequency of occurrence, with the right foot, left foot, and head [24, 42]. This was also found in this study, were goals predominantly occurred with right foot, and only 2 with head in females versus 5 in males. These results are supported by physiological studies that prove that in female players, the activation of the iliacus muscle in the kick- 
ing leg presents lower values than in male players [43].

In addition, the foot velocity at the time of ball impact and the ball velocity have been reported to be lower in female than in male soccer players [44, 45]. Moreover, it has been shown that the majority of goals scored in women's soccer are the result of open play as opposed to set plays [46]. This aspect should be considered in the specific and tactical preparation of games.

Analysis of World Cups from years 1982-2014 indicates that $25-35 \%$ of goals result from free kicks or corner kicks [47-50], and it has been reported that during the 2007 Women's World Cup there was an increased scoring rate for direct free kicks if these were taken within a 7-m radius of the penalty spot [51].

It was previously proved that crosses directed towards the centre of the penalty area or in the zones in front of the goalposts increased the chances of scoring [19], whereas another study could not find any correlation between position and scoring [52]. It was also suggested that corner kicks were more successful when played near the 6-yard line [53].

We found differences in total values in men's and women's soccer also with regard to the last pass before goal. It was clearly observable that in female soccer, the last pass was predominantly in the offensive zone, and in male players, there was a better balance between the intermediate (middle) and offensive zone.

Another evident finding in this study was that in males, there were more goals without a pass before the finish than those obtained after passing in the midfield. In females, the number of goal achievements without a pass before was also considerable. In none of the genders, goals scored with a previous pass from the defensive zone were observable.

It has been verified that the effectiveness of the offensive action increases with respect to the proximity of the ball's recovery in relation to the opposing goal [37]. With decreasing distance from the goal, the chance of scoring increases. This was to be expected and is consistent with the results of a previous study [54]. Potentially, this can be explained by a shorter amount of time that the goalkeeper has to react and/or a higher target accuracy [51].

With respect to the finishing zone, we observed a large difference in zone I (central zone outside the area), with 5 goals for male and 2 for female players. Zones $\mathrm{C}, \mathrm{F}$, and I, the central zones of the attack, were areas in which more goals were obtained in total and in both genders. Despite this, no statistically significant differences were observed between genders.

In zone $\mathrm{C}$, the closest to the goal, a greater number of goals were obtained by female as compared with male soccer players, possibly owing to some physical characteristics, which should be further studied.

The limitation of this study relates to the fact that the results reflect the characteristics of the specific investigated professional team, not the patterns of women's and men's soccer in general.

In the future, research related to this topic could be extended to 2 or more seasons and involve teams of different levels, as well as some specifications such as age, playing position, physical characteristics, and also the effectiveness of the offensive phase of a soccer game after ball recovery (either successful or unsuccessful).

\section{Conclusions}

The presented study raises the relevance of a scientific approach to goal characterization after ball recovery, a specific aspect of a soccer game, directly related to the main objective of scoring and not conceding goals.

It is clearly evident that some differences exist between genders related to ball recovery and environmental goal achievement. This should be assumed in the daily training process at various levels: tactical, physical, and even psychological or emotional.

Even so, the approximation between dynamics related to goal accomplishment in male and female soccer players is evident and brings new challenges for research and sport, namely, to better organize the training process and improve performance.

Another relevant aspect is the obvious pertinence of an increasingly individualized preparation in soccer, observable in this study in both genders from ball recovery to goal achievement.

\section{Disclosure statement}

The authors gratefully acknowledge the financial support from the Polytechnic Institute of Setúbal.

\section{Conflict of interest}

The authors state no conflict of interest.

\section{References}

1. Wisløff U, Helgerud J, Hoof J. Strength and endurance of elite soccer players. Med Sci Sports Exerc. 1998;30(3): 462-467; doi: 10.1097/00005768-199803000-00019.

2. Rienzi E, Drust B, Reilly T, Carter JE, Martin A. Investigation of anthropometric and work-rate profiles of elite South American international soccer players. J Sports Med Phys Fitness. 2000;40(2):162-169.

3. Di Salvo V, Baron R, Tschan H, Calderon MFJ, Bachl N, Pigozzi F. Performance characteristics according to 
M. Espada, C. Fernandes, C. Martins, H. Leitao, T. Figueiredo, F. Santos, Goal characterization in soccer

playing position in elite soccer. Int J Sports Med. 2007; 28(3):222-227; doi: 10.1055/s-2006-924294.

4. Rampinini E, Coutts A, Castagna C, Sassi R, Impellizzeri F. Variation in top level soccer match performance. Int J Sports Med. 2007;28(12):1018-1024; doi: 10.1055/ s-2007-965158.

5. Lago-Peñas C. The role of situational variables in analysing physical performance in soccer. J Hum Kinet. 2012;35:89-95; doi: 10.2478/v10078-012-0082-9.

6. Gómez MA, Lago-Peñas C, Pollard R. Situational variables. In: McGarry T, O’Donoghue P, Sampaio J (eds.), Routledge handbook of sports performance analysis. London: Routledge; 2013; 259-269.

7. Garganta J. Football and science. Science and football [in Portuguese]. Revista Digital. 2001;7(40). Available from: https://www.efdeportes.com/efd40/fcienc.htm.

8. Luhtanen P, Belinskij A, Häyrinen M, Vänttinen T. A comparative tournament analysis between the EURO 1996 and 2000 in soccer. Int J Perform Anal Sport. 2001;1(1):74-82; doi: 10.1080/24748668.2001.11868250.

9. Horn R, Williams M, Ensum J. Attacking in central areas: a preliminary analysis of attacking play in the 2001/ 2002 FA premiership season. Insight FA Coach Assoc J. 2002;5(3):31-34.

10. Capranica L, Tessitore A, Guidetti L, Figura F. Heart rate and match analysis in pre-pubescent soccer players. J Sports Sci. 2001;19(6):379-384; doi: 10.1080/02640 4101300149339.

11. Fozooni B. Iranian women and football. Cult Stud. 2008; 22(1):114-133; doi: 10.1080/09502380701480634.

12. Bayer C. Teaching team sports games [in French]. Paris: Vigot; 1986.

13. Grehaigne J, Marchal D, Duprat E. Regaining possession of the ball in the defensive area in soccer. In: Spinks W, Reilly T, Murphy A (eds.), Science and football IV. London: Routledge; 2002; 112-120.

14. Barreira D, Garganta J, Anguera MT. In search of nexus between attacking game-patterns, momentaneous score and type of ball recovery in European Soccer Championship 2008. In: Hughes M, Dancs H, Nagyváradi K, Polgár T, James N, Vuckovic G, et al. (eds.), $5^{\text {th }}$ International Christmas Sport Scientific Conference: Qualitative and Quantitative Research in Sports Science. Szombathely: Hungary; 2011; 226-237.

15. Barreira D, Garganta J, Machado J, Anguera MT. Effects of ball recovery on top-level soccer attacking patterns of play. Rev Bras Cineantropom Desemp Hum. 2014;16(1):36-46; doi: 10.5007/1980-0037.2014v16 n1p36.

16. Lago-Ballesteros J, Lago-Peñas C, Rey E. The effect of playing tactics and situational variables on achieving score-box possessions in a professional soccer team. J SportSci.2012;30(14):1455-1461;doi:10.1080/02640414. 2012.712715 .

17. Tenga A, Holme I, Ronglan L, Bahr R. Effect of playing tactics on goal scoring in Norwegian professional soccer.
J Sports Sci. 2010;28(3):237-244; doi: 10.1080/026 40410903502774.

18. Pollard R, Reep C. Measuring the effectiveness of playing strategies at soccer. Statistician. 1997;46(4):541-550; doi: 10.1111/1467-9884.00108.

19. Carling C, Williams AM, Reilly T. Handbook of soccer match analysis: a systematic approach to improving performance. Abingdon: Routledge; 2005.

20. Janković A, Leontijević B, Jelušić V, Pašić M, Mićović B. Influence of tactics efficiency on results in Serbian soccer super league in season 2009/2010. J Phys Educ Sport. 2011;11(1):32-41.

21. Garganta J, Maia J, Basto F. Analysis of goal-scoring patterns in European top level soccer teams. In: Reilly T, Bangsbo J, Hughes M (eds.). Science and football III. Abingdon: Taylor \& Francis; 1997; 246-250.

22. Hughes C. The winning formula. London: William Collins Sons \& Co Ltd; 1990.

23. Gréhaigne J. The organization of the game in football [in Spanish]. Barcelona: INDE; 2001.

24. Santos F, Mendes B, Maurício N, Furtado B, Sousa P, Pinheiro V. Goal analysis in elite soccer teams in the 2013-2014 season [in Portuguese]. Rev Desporto Atividade Fis. 2016;8(1):11-22.

25. Santos F, Sarmento H, Mendes B, Maurício N, Furtado B, Sousa P, et al. Complementary analysis of goal in football through notational analysis, sequential analysis and T-patterns detection [in Portuguese]. Rev Bras Futsal Futebol. 2017;9(34):238-249.

26. Gabin B, Camerino O, Anguera MT, Castañer M. Lince: multiplatform sport analysis software. Procedia Soc Behav Sci. 2012;46:4692-4694; doi: 10.1016/j.sbspro. 2012.06.320.

27. Blanco-Villaseñor A, Castellano J, Hernández-Mendo A, Sánchez-López C, Usabiaga O. Application of the generalizability theory in sport to study the validity, reliability and estimation of samples [in Spanish]. Rev Psicol Deporte. 2014;23(1):131-137.

28. Brewer CJ, Jones RL. A five-stage process for establishing contextually valid systematic observation instruments: the case of Rugby Union. Sport Psychol. 2002;16(2):138-159; doi: 10.1123/tsp.16.2.138.

29. Cohen J. A coefficient of agreement for nominal scales. Educ Psychol Meas. 1960;20(1):37-46; doi: 10.1177/ 00131644002000104.

30. Bradley DR, Cutcomb S. Monte Carlo simulations and the chi-square test of independence. Behav Res Methods Instrum. 1977;9(2):193-201; doi: 10.3758/BF03214499.

31. Ali A. Measuring soccer skill performance: a review. Scand J Med Sci Sports. 2011;21(2):170-183; doi: 10.1111/j.1600-0838.2010.01256.x.

32. Stølen T, Chamari K, Castagna C, Wisløff U. Physiology of soccer: an update. Sports Med. 2005;35(6):501-536; doi: 10.2165/00007256-200535060-00004.

33. Barreira D, Garganta J, Guimaraes P, Machado J, Anguera MT. Ball recovery patterns as a performance indicator in elite soccer. Proc Inst Mech Eng P J Sport Eng 
Technol. 2014;228(1):61-72; doi: 10.1177/175433711 3493083.

34. Barreira D, Garganta J. Sequential pattern of defenceattack transition in Portuguese Championship 2004/ 2005 football matches. $1^{\text {st }}$ International Sports Games Congress: Views and Contexts of Performance from Initiation to Accomplishment [in Portuguese]. Porto: University of Porto; 2007.

35. Barreira D, Ribeiro R, Garganta J, Anguera MT. Book of abstracts of the IV European Congress of Methodology: $27^{\text {th }}$ Biennial Conference of the Society for Multivariate Analysis in the Behavioural Sciences, EAMSMABS 2010. Potsdam; 2010.

36. Castelo J. Football. Dynamic organization of the game [in Portuguese]. Lisboa: Edições Universitárias Lusófonas; 2009.

37. Tenga A, Ronglan L, Bahr R. Measuring the effectiveness of offensive match-play in professional soccer. Eur J Sport Sci. 2010;10(4):269-277; doi: 10.1080/174613 90903515170.

38. Tenga A, Sigmundstad E. Characteristics of goal-scoring possessions in open play: comparing the top, inbetween and bottom teams from professional soccer league. Int J Perform Anal Sport. 2011;11:545-552; doi: 10.1080/24748668.2011.11868572.

39. Liu H, Gomez MÁ, Lago-Peñas C, Sampaio J. Match statistics related to winning in the group stage of 2014 BrazilFIFA World Cup.J Sports Sci. 2015;33(12):12051213; doi: 10.1080/02640414.2015.1022578.

40. Link D. Using of invasion profiles as a performance indicator in soccer. In: Heazlewood I (ed.), Proceeding of International Association of Computer Science in Sports Conference. Darwin; 2014.

41. Johnson JG. Cognitive modeling of decision making in sports. Psychol Sport Exerc. 2006;7(6):631-652; doi: 10.1016/j.psychsport.2006.03.009.

42. Baptista B, Pinheiro V. Análise da obtenção do golo no futebol profissional. Um estudo observacional na Liga Portuguesa. Rev Desporto Atividade Fis. 2014;7(2).

43. Brophy RH, Backus S, Kraszewski AP, Steele BC, Ma Y, Osei D, et al. Differences between sexes in lower extremity alignment and muscle activation during soccer kick. J Bone Joint Surg Am. 2010;92(11):2050-2058; doi: 10.2106/JBJS.I.01547.

44. Clagg SE, Warnock A, Thomas JS. Kinetic analyses of maximal effort soccer kicks in female collegiate athletes. Sports Biomech. 2009;8(2):141-153; doi: 10.1080/ 14763140902752106.

45. Barfield WR, Kirkendall DT, Yu B. Kinematic instep kicking differences between elite female and male soccer players. J Sports Sci Med. 2002;1(3):72-79.

46. Kirkendall D, Dowd W, DiCicco A. Patterns of successful attacks: a comparison of the men's and women's World Cup. Rev Fútbol Cien. 2002;1(1):29-36.

47. Jinshan X, Xiaoke C, Yamanaka K, Matsumoto M. Analysis of the goals in the $14^{\text {th }}$ World Cup. In: Reilly T,
Clarys J, Stibbe A (eds.), Science and football II. London: Taylor \& Francis; 1993; 203-205.

48. Yiannakos A, Armatas V. Evaluation of the goal scoring patterns in European Championship in Portugal 2004. Int J Perform Anal Sport. 2006;6(1):178-188; doi: 10.1080/24748668.2006.11868366.

49. Acar M, Yapicioglu B, Arikan N, Yalcin S, Ates N, Ergun M. Analysis of goals scored in the 2006 World Cup. In: Reilly T, Korkusuz F (eds.), Science and football VI. Abingdon: Routledge; 2009; 235-242.

50. Njororai W. Analysis of goals scored in the 2010 World Cup soccer tournament held in South Africa. J Phys Educ Sport. 2013;13(1):6-13; doi: 10.7752/jpes.2013.01002.

51. Alcock A. Analysis of direct free kicks in the women's football World Cup 2007. Eur J Sport Sci. 2010;10(4): 279-284; doi: 10.1080/17461390903515188.

52. Casal AC, Maneiro R, Ardá T, Losada JL, Rial A. Effectiveness of indirect free kicks in elite soccer. Int J Perform Anal Sport. 2014;14(3):744-760; doi: 10.1080/ 24748668.2014.11868755.

53. Taylor JB, James N, Mellalieu SD. Notational analysis of corner kicks in English Premier League soccer. In: Reilly T, Cabri J, Araújo D (eds.), Science and football V. Abingdon: Routledge; 2005; 229-234.

54. Pollard R, Ensum J, Taylor S. Estimating the probability of a shot resulting in a goal: the effects of distance, angle and space. Int J Soccer Sci. 2004;2(1):50-55. 